\title{
Predicting of Land Surface Temperature Distribution in Freetown City, Sierra Leone by Using Polynomial Curve Fitting Model
}

\author{
Elhadi K. Mustafa1', Guoxiang Liu1, Abubakr Hassan', Mohamed A. Damos', Musa Tarawally² \\ ${ }^{1}$ Department of Surveying and Geo-Informatics, Faculty of Geosciences and Environmental Engineering, Southwest Jiaotong \\ University, Chengdu, China \\ ${ }^{2}$ School of Resources and Environment, University of Electronic Science and Technology of China, Chengdu, China \\ Email: musatarawally28@yahoo.com, elhadik30@gmail.com
}

How to cite this paper: Mustafa, E.K., Liu, G.X., Hassan, A., Damos, M.A. and Tarawally, M. (2020) Predicting of Land Surface Temperature Distribution in Freetown City, Sierra Leone by Using Polynomial Curve Fitting Model. Journal of Geographic Information System, 12, 531-544.

https://doi.org/10.4236/jgis.2020.125031

Received: September 20, 2020

Accepted: October 27, 2020

Published: October 30, 2020

Copyright $\odot 2020$ by author(s) and Scientific Research Publishing Inc. This work is licensed under the Creative Commons Attribution International License (CC BY 4.0).

http://creativecommons.org/licenses/by/4.0/

\section{(c) (i) Open Access}

\begin{abstract}
Global warming has attracted much concern about the worldwide organization, civil society groups, researchers, and so forth because the worldwide surface temperature has been expanding. This investigation intends to assess and compare the ability of a combination of land cover indices to predict the future distribution of land surface temperatures in Freetown using the Polynomial model analysis. Landsat satellite images of 1988, 1998, 2000, 2010, and 2018 of the Freetown Metropolitan zone were utilized for analysis. The investigation had adopted two land covers indices, Modification of normalized difference water index and Urban Index (UI) (e.g., MNDWI and UI) and applied a multi regression equation for forecasting the future LST. The stimulation results propose that the development will be accompanied by surface temperature increases, especially in Freetown's western urban area. The temperature prevailing in the west of the metropolitan area may increase in the city somewhere in the range from 1988 to 2018. Additionally, the results of the LST prediction show that the model is perfect. Our discoveries can be represented as a helpful device for policymakers and community awareness by giving a scientific basis for sustainable urban planning and management.
\end{abstract}

\section{Keywords}

Global Warming, Land Surface Temperature, Polynomial Curve Fitting, Land Cover Indices

\section{Introduction}

The urban heat island (UHI) impact shows a higher air and land surface tem- 
perature (LST) in urban regions in contrast with the encompassing rural area, generated by high levels of near-surface energy emission, solar radiation absorption of ground objects, and low rates of evapotranspiration [1]. This is as a result of urbanization and overpopulation. These have resulted in most important human activities, creating enormous impacts on the ecosystem at the local, regional, and global scales. It includes converting natural land surfaces into anthropogenic impervious surfaces due to the introduction of low and high albedo materials, which may lead to dramatic climate changes; consequently, an urban climate is warming systematically since the last decades. Such heat rise and warming can be embraced by numerous biophysical well-being intricacies like heat stress, air contamination, and other well-being-related issues [2]. In recent years, studies have proved that the developed area and bare land accelerate UHI's impact, though green space and water diminish the UHI intensity [3] [4]. Therefore, it is essential to study the prediction of land surface distribution [5]. This is a very vital in urban areas of developing countries that are experiencing an increase in land surface temperature, which may result in adverse climate and related factors. Studies have been confined to few cities in Africa, mainly in Ikom city in Nigeria, Harare metropolitan city in Zimbabwe. For example, Muduako et al., 2016 reported that LST in an urban area is one factor associated with urban heat rise and microclimatic warming within a city [6]. Mushore et al., 2017 documented that urban growth will increase warming and result in future high temperatures unless mitigation efforts are strengthened [7]. To the best of our knowledge, little work has been implemented to predict land surface distribution in Freetown, Sierra Leone, and quantify the implication of land surface temperature. Freetown is a coastal city with a rapid growth in urbanization, and such factor is expected to affect the increase in surface temperature. Such a study is vital both given quantifying the effects of expansion on lower tropospheric temperature and in developing knowledge on growth implications on future climate and thermal comfort on urban residents. Space-borne remote sensing has the benefit of simultaneously observing over large areas enabling spatial analysis and direct comparison in space. Remote sensing satellites such as Landsat have many benefits, including large stores of archival data and continuous improvements in data quality over time. For example, Landsat has archival data dating as far back as 1972, making it an important data source for detecting land surface changes over long periods. This paper used space-borne multi-spectral Landsat imagery to predict the future land surface temperature in Freetown city in Sierra Leone from 2018 to 2026 .

\section{Materials and Method}

\subsection{Study Area}

Study area Freetown is the first capital of Sierra Leone (Figure 1) that lies between latitude $8^{\circ} 05^{\prime} \mathrm{N}$ and $8^{\circ} 30^{\prime} \mathrm{N}$ and extends between longitudes $12^{\circ} 50^{\prime} \mathrm{W}$ and $13^{\circ} 20^{\prime} \mathrm{W}$. It is the major port city on the Atlantic Ocean. It is located in the 


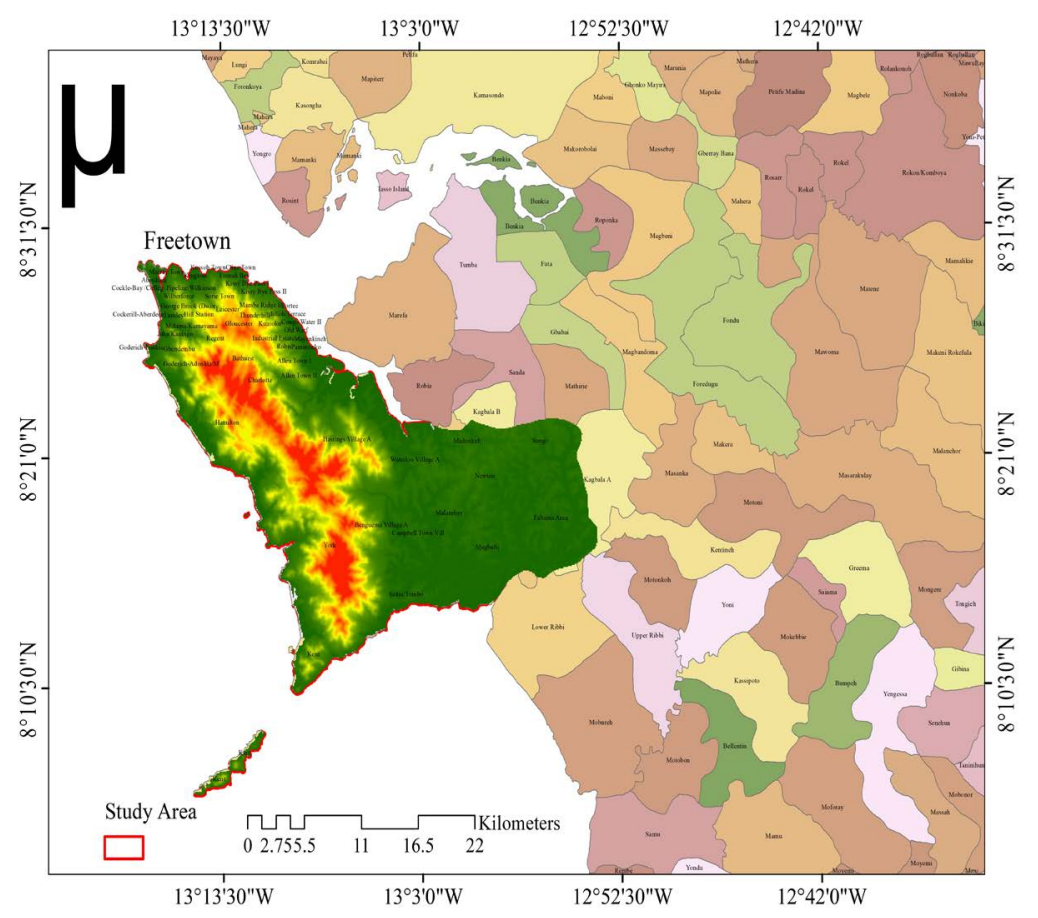

Figure 1. Geographical setting of the study areas.

western area of Sierra Leone. Freetown experiences a tropical climate with a rainy season from May to October and a dry season from November to April. The yearly average minimum temperature for Freetown is around $23.8^{\circ} \mathrm{C}$, while the average maximum temperature is $29.9^{\circ} \mathrm{C}$. annual mean minimum temperature [8]. The topography of Freetown is undulated. Elevation ranges between $100 \mathrm{~m}$ and $700 \mathrm{~m}$, with slopes exceeding $50 \mathrm{~m}$ above sea level. The prevailing winds are the southwest monsoon during the wet season and the northeastern harmattan, a dust-laden wind from the Sahara Desert during the dry season. The red-bordered areas (study areas) are a rapidly developing area.

\subsection{Data Used}

This study uses cloud-free and geometrically corrected Landsat imagery from the Earth Resources Observation and Science (EROS) center through the United States Geological Survey (USGS) Global Visualization Viewer, map projection of the collected satellite images is Universal Transverse Mercator (UTM) within Zone $28 \mathrm{~N}$-Datum World Geodetic System (WGS) 84 (Table 1). Various software packages were utilized because each one has strength in some operations needed for this study.

\subsection{Image Preprocessing}

Landsat satellite images (Landsat 5 TM and Landsat 8 OLI/TIRS) with metadata (MTL) file for the study area were utilized for assessing land surface temperature (LST). The satellite images obtained are processed by a set of pre-processing procedures. The pre-processing in clouded radiometric calibration, atmospheric 
Table 1. Image information will be used in the study.

\begin{tabular}{cccccc}
\hline \multirow{2}{*}{ Sensor information } & \multicolumn{5}{c}{ Image information } \\
\cline { 2 - 6 } & Date (dd-mm-yy) & Resolution & Path/row & Bands & Source \\
\hline Landsat4/5 TM & 26.12 .1988 & $30,120 \mathrm{~m}$ & $202 / 54$ & $3,5,7,6$ & Usgs.gov \\
Landsat4/5 TM & 09.3 .1998 & $30,120 \mathrm{~m}$ & $202 / 54$ & $3,5,7,6$ & Usgs.gov \\
Landsat4/5 TM & 03.2 .2000 & $30,120 \mathrm{~m}$ & $202 / 54$ & $3,5,7,6$ & Usgs.gov \\
Landsat4/5 TM & 22.2 .2010 & $30,120 \mathrm{~m}$ & $202 / 54$ & $3,5,7,6$ & Usgs.gov \\
Landsat8 OLI_TIRS & 12.2 .2018 & $30,100 \mathrm{~m}$ & $202 / 54$ & $4,6,7,10$ & Usgs.gov \\
\hline
\end{tabular}

correction (dark-object subtraction) using the Envi 5.3 and geometrical distortions correction. After the pre-processing procedure, the satellite images are again re-sampled with pixel sizes of $30 \times 30 \mathrm{~m}$ for all bands which also includes the thermal band. As referenced before $30 \mathrm{~m}$ goals resolution reflective bands of Land-sat images obtained from various seasons were piled up into a single multi-band record for the categorization.

\subsection{LST Recoupment from the Information in Thermal Infrared Data}

In the proposed research, a mean thermal infrared image containing digital numbers was analyzed every year through computing 2 images collected in each month using LST based procedures that were proposed by [9]. The procedure suggested involves 1) transformation of digital number data contained inside Landsat images to radiance, 2) transformation of radiance into temperature of blackbody and 3) blackbody temperature due to brightness into temperature of land surface (emissivity correction). Adopted from [10] emissivity mapping of land surface was calculated using NDVI.

\subsubsection{Transformation of the Digital Number (DN) to Spectral Radiance}

As shown in equation no. 1 which is considered by [11], data gathered from digital numbers are transformed to spectral radiance. Data from digital numbers are of the TIR bands of ETM+ and TM5 images for individual years. Then the use of Equation no. (2) thermal infrared images of Landsat 8were transformed considering the standard of USGS.

$$
\begin{gathered}
L_{\lambda}=L_{\min }+\frac{L_{\text {max }}-L_{\text {min }}}{Q C A L_{\text {max }}-Q C A L_{\min }}\left(D N-Q C A L_{\min }\right) \\
=M_{L} \times Q_{c a l}+A_{L}
\end{gathered}
$$

In Equations (1) and (2), $L_{\lambda}$ denotes spectral radiance in $\mathrm{W} /\left(\mathrm{m}^{2} \mathrm{sr} \mu \mathrm{m}\right)$ gained by the sensor found from each pixel from the Landsat imagery. Band specific multiplicative is denoted by ML and rescaling factors which are gathered from MTL image file are found to be additive and is denoted using the term by AL. $D N$ of each image and maximum $D N$ is represented by $Q_{c a l}$ and $Q C A L_{\max }$. The value of Qcal and $Q C A L_{\max }$ for the 16-bit Landsat 8 is 65535 and for other Landsat missions is 255 respectively. $Q C A L_{\min }$ is the least $\mathrm{DN}(0)$. Radiances from top of the 
atmosphere (TOA) are denoted as $L_{\max }$ and $L_{\min }$ that are scaled to $Q C A L_{\max }$ and $Q C A L_{\min }$ in $\mathrm{W} /\left(\mathrm{m}^{2} \mathrm{sr} \mu \mathrm{m}\right)$, respectively.

\subsubsection{Calculation Brightness Temperature of Blackbody Using Spectral Radiance}

With the use of Equation (3) the radiant images were transformed into temperature detected in blackbody [12].

$$
T_{b}=\frac{K_{2}}{\ln \left\{\left(\frac{K_{1}}{L_{\lambda}}\right)+1\right\}}
$$

In the above Equation brightness temperature in Kelvin unit is measured using sensor which is denoted with $T_{b}$, spectral radiance in $\mathrm{W} /\left(\mathrm{m}^{2} \mathrm{sr} \mu \mathrm{m}\right)$ is denoted with $L_{\lambda}$ and through image MTL file prelaunch calibration constants in Kelvin unit is obtained. These are represented as $K_{1}$ and $K_{2}$. Error in measurement of surface temperature can arise during the execution process due to detection of earth as a blackbody because of its brightness [12]. To minimize these error values, emissivity correction is performed to attain land surface temperature (LST) from $\mathrm{Tb}$ using Equation (4), [13].

\subsubsection{Retrieval of Surface Emissivity $(\varepsilon)$}

A threshold method was suggested by [14] to achieve land surface emissivity from Normalized Difference Vegetation Index (NDVI) threshold method. If NDVI < 0.2 then pixels are acknowledged as barren land. The emissivity of these barren lands was derived from red spectral region. If NDVI $>0.5$ then pixels are acknowledged as lands thoroughly covered with plants or agricultural fields and its emissivity value was estimated to be 0.99 [10]. When NDVI value lies between the range of 0.2 to 0.5 then pixels are acknowledged as partially covered with vegetation. Using Equation (4) the emissivity is obtained.

$$
\varepsilon=\varepsilon_{v} P_{v}+\varepsilon_{s}\left(1-P_{v}\right)+\Delta \varepsilon
$$

where $\varepsilon_{v}$ the emissivity of vegetation coverage, $\varepsilon_{s}$ is the soil surface emissivity and, $P_{v}$ is computed to obtain the proportion of vegetation using Equation (5).

$$
\left[\frac{\mathrm{NDVI}-\mathrm{NDVI}_{s}}{\mathrm{NDVI}_{v}-\mathrm{NDVI}_{s}}\right]^{2}
$$

where $\mathrm{NDVI}_{s}$ is the NDVI value of pure soil and $\mathrm{NDVI}_{v}$ is the NDVI values of pure vegetation derived from NDVI image. $\Delta \varepsilon$ in Equation (7) indicates distribution of the land surfaces according to its geometry in addition to its the internal reflection. The value of internal reflection is very low for the ordinary and uniform surfaces [10]. The value of internal reflection is however found to be $2 \%$ for rough and heterogeneous surface. $\Delta \varepsilon$ is calculated using Equation (6)

$$
\left(1-\varepsilon_{s}\right)\left(1-P_{v}\right) F \varepsilon_{v}
$$

where shape factor is denoted by $F$. The mean value for different land surfaces according to its distributions based on its geometry is assumed as 0.5 . 
Summarizing Equation (5) and Equation (6), the final equation to calculate emissivity estimation is given as Equation (7).

$$
\varepsilon=m P_{v}+n
$$

where $\mathrm{m}$ and $\mathrm{n}$ co-efficient are calculated as below in Equation (8):

$$
m=\varepsilon_{v}-\varepsilon_{s}-\left(1-\varepsilon_{s}\right) F \varepsilon_{v} \text { and } n=\varepsilon_{s}+\left(1-\varepsilon_{s}\right) F \varepsilon_{v}
$$

\subsubsection{Brightness Temperature to LST}

$$
\mathrm{LST}=\frac{T_{b}}{1+\left\{\lambda T_{b}\left(\frac{K}{\rho}\right) \times \ln \varepsilon\right\}}
$$

In the above Equation (9), wavelength of emitted radiance $(11.5 \mu \mathrm{m})$ [11] is represented by $\lambda, \rho=h c l \sigma$ [15], $K$ is the Stefan-Boltzmann's constant, $h$ is the Planck's constant, velocity of light $\left(2.998 \times 10^{8} \mathrm{~ms}^{-1}\right)$ by $c$ and surface emissivity by $\varepsilon$. Finally, the derived LST values were converted to the conventional Degree Celsius $\left({ }^{\circ} \mathrm{C}\right)$ unit by adding the absolute zero which is approximately minus $273.15^{\circ} \mathrm{C}$. Finally retrieve the (LST) as shown in Figure 2.

\subsection{Simulation of LST Distribution in Freetown Using Land Cover Indices}

\subsubsection{Computation Indices for Land Surfaces of Urban and Vegetation Areas}

Table 2 involves urban indices and indices of vegetation. These were estimated through a digital number of measured bands. As recently referenced, the ultimate objective is to investigate the superiority in a relationship's characteristics with the surface temperature. In addition to this to perceive indices with highest grounded capacity for assessing temperature of surfaces of urban areas, a couple of indices were tried. Simulating LST using polynomial curve fitting was shown in Figure 3.
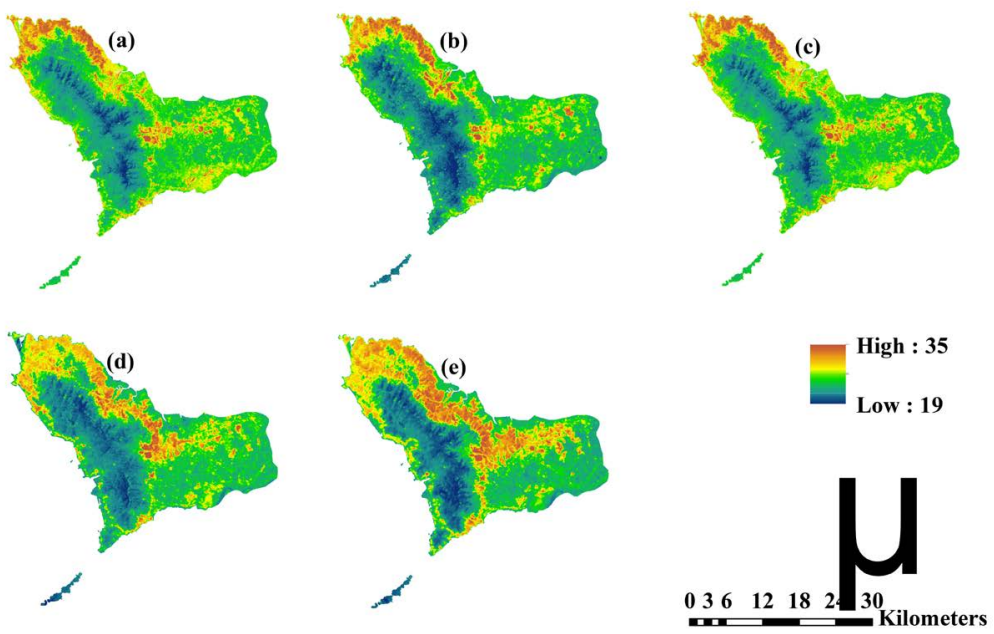

Figure 2. LST maps of Freetown city on different dates ((a) 26 December 1988, (b) 9 March 1998, (c) 3 February 2000, (d) 22 February 2010, (e) 12 February 2018). 


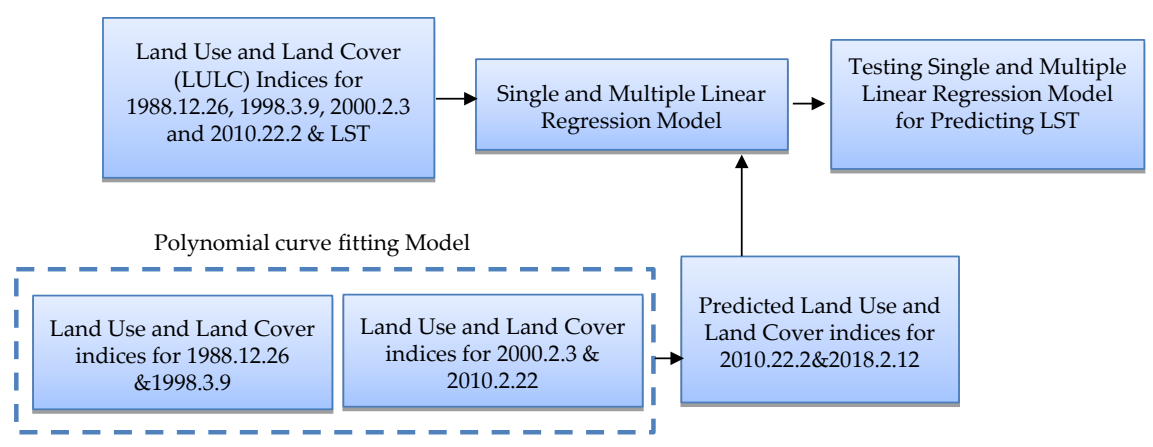

Figure 3. A detailed flowchart for simulating LST using polynomial curve fitting.

Table 2. Derivation of urban and vegetation indices from Landsat data.

\begin{tabular}{|c|c|c|c|}
\hline \multirow{2}{*}{$\begin{array}{l}\text { Derivation } \\
\text { of Indices }\end{array}$} & \multicolumn{3}{|c|}{ Urban and Vegetation Indices } \\
\hline & Index & Computation & Ref \\
\hline 1 & $\begin{array}{l}\text { Normalized Difference } \\
\text { Built-up Index (NDBI) }\end{array}$ & $\mathrm{NDBI}=\mathrm{WIR} 1+\mathrm{NIR} / \mathrm{WIR} 1+\mathrm{NIR}$ & [16] \\
\hline 2 & Urban Index (UI) & $\mathrm{UI}=\mathrm{WIR} 2+\mathrm{NIR} / \mathrm{WIR} 2+\mathrm{NIR}$ & [17] \\
\hline 3 & $\begin{array}{c}\text { Normalized Difference } \\
\text { Vegetation Index (NDVI) }\end{array}$ & $\mathrm{NDVI}=\mathrm{NIR}-\mathrm{RED} / \mathrm{NIR}+\mathrm{RED}$ & [18] \\
\hline 4 & $\begin{array}{c}\text { Modified Normalized } \\
\text { Difference Water Index (MNDWI) }\end{array}$ & NDWI = GREEN - NIR/GREENNIR & [19] \\
\hline
\end{tabular}

\subsubsection{Correlation Analyses between LST and Indices}

Evaluating temperatures of land surfaces with the use of various factors requires high value of correlation between the predictor variables and temperature measured at land surfaces, with no inter-factor show evaluation of indices for quality assessment of correlation with LST. The indices that exceptionally correlate with LST were chosen and applied to develop a linear regression model in order to analyze future temperatures of land surfaces. To analyze the relation between land cover indices (e.g., UI, MNDWI, NDVI and NDBI) and the LST for each of the periods multiple linear regression models are designed. The investigation outputs demonstrate statistically significant correlations which are valid for an entire year [5]. Land cover indices and LST values were mined from each pixel in the designated area of study for individual point data type in order to achieve this objective. These points were utilized to calibrate the linear regression model [20]. The model offers a general idea about the correlation between LST and LULC indices. This realization is relatively coherent with those narrated by other earlier researches [21].

\subsubsection{Polynomial Curve Fitting for Land Use Land Cover Indices Prediction}

The Land Use Land Cover Indices for 26.12.1988, 9.3.1998, 3.2.2000, 22.2.2010, and 12.2.2018 for the same seasons were the input variable in the polynomial curve fitting [13] to map future state of the indices for 2010 and 2018, Similarly, the Land Use Land Cover Indices 22.2.2010 and 12.2.2018 was used in polynomi- 
al curve fitting analysis to predict the state of the Land Use Land Cover Indices in 2026, as shown below:

$$
\left[\begin{array}{ccccc}
m & \sum x_{i} & \sum x_{i}^{2} & \cdots & \sum x_{i}^{n} \\
\sum x_{i} & \sum x_{i}^{2} & \sum x_{i}^{3} & \cdots & \sum x_{i}^{n+1} \\
\sum x_{i}^{2} & \sum x_{i}^{3} & \sum x_{i}^{4} & \cdots & \sum x_{i}^{n+2} \\
\vdots & \vdots & \vdots & \ddots & \vdots \\
\sum x_{i}^{n} & \sum x_{i}^{n+1} & \sum x_{i}^{n+2} & \cdots & L \sum x_{i}^{2 n}
\end{array}\right]\left[\begin{array}{c}
p_{1} \\
p_{2} \\
p_{3} \\
\vdots \\
p_{n+1}
\end{array}\right]=\left[\begin{array}{c}
\sum y_{i} \\
\sum x_{i} y_{i} \\
\sum x_{i}^{2} y_{i} \\
\vdots \\
\sum x_{i}^{n} y_{i}
\end{array}\right]
$$

Curve fitting over $m$ pairs of data $\left(x_{1}, y_{1}\right),\left(x_{2}, y_{2}\right), \cdots,\left(x_{m}, y_{m}\right)$ is a process of obtaining a polynomial regression between the two pairs as follows:

$p(x)=P_{1} x^{n}+P_{2} x^{n-1}+\cdots+P_{n} x+P_{n+1}$; where, $p(x)$ is a curve fitting of data pairs; $p_{1}, p_{2}, \cdots, p_{n+1}$ are the model variables, and the $x_{1}, \cdots, x_{n}$ are the $n$ inputs variables. These input variables have a dependency on the possible data available across. Through the current study, the unknown parameters are found using the least square method. At last Land Use Land Cover Indices predictions were converted into land surface temperature distributions for 2010, 2018 and 2026 in the same seasons through multiple linear regression analysis functions.

\subsubsection{Prediction Accuracy Assessment for LST}

The proposed method is applied to forecast temperature of land surfaces for the year 2016 and its rate of accuracy in predicting was measured through Mean Absolute Percentage error. [MAPE]-Equation (10)—(Owen, Carlson et al. 1998).

$$
\text { MAPE } \%=\frac{1}{N} \sum_{i=1}^{N}\left|\left(T_{\text {predicted }}-T_{\text {observed }}\right) / T_{\text {observed }}\right| * 100
$$

where: the modeled surface temperature and the actual land surface temperature recorded from Landsat data for the ith pixel is denoted by $T_{\text {predictedand }} T_{\text {observed }}$. Root Mean Square Error and ration RMSE/std can also be regarded as the measure for calculating accuracy of the prediction model in forecasting temperature. Land surface temperature distribution for the period from 2026 is then found using the prediction model after the accuracy assessment.

\section{Results and Discussion}

\subsection{Monitoring and Assessing LST Changes}

The LST maps of Free Town in 1988, 1998, 2000, 2010 and 2018 are illustrated in Figure 3 and the descriptive statistics of the retrieved LST values are summarized in Table 3. In $12 / 12 / 1988$, the LST ranged from $17.11^{\circ} \mathrm{C}$ to $30.83^{\circ} \mathrm{C}$ with an average $21.23^{\circ} \mathrm{C}$, in 09.3 .1998 , the LST ranged from $17.93^{\circ} \mathrm{C}$ to $31.72^{\circ} \mathrm{C}$ with a mean $23.94^{\circ} \mathrm{C}$. in 03.2 .2000 , the $\mathrm{LST}$ ranged from $18.38^{\circ} \mathrm{C}$ to $32.05^{\circ} \mathrm{C}$ with an average $23.28^{\circ} \mathrm{C}$. in 2010 , the LST ranged from $20.6^{\circ} \mathrm{C} 2$ to $33.5^{\circ} \mathrm{C} 6$ with a mean $25.25^{\circ} \mathrm{C}$. in 2018 , the LST ranged from $20.61^{\circ} \mathrm{C}$ to $34.51^{\circ} \mathrm{C}$ with a mean $26.72^{\circ} \mathrm{C}$. From these data, the highest LST was in 2018 and the lowest LST in 1988. The LST was increased from one year to another due to development of human activities and climatic change. The high levels of LST were concentrated in the northern parts 
Table 3. Descriptive statistics of LST for different times.

\begin{tabular}{cccccc}
\hline \multirow{2}{*}{ Statistics Information } & \multicolumn{5}{c}{ Descriptive statistics of LST } \\
\cline { 2 - 6 } & YEAR & Mean & Min & Max & St \\
\hline 1 & 26.12 .1988 & 21.23 & 17.11 & 30.83 & 1.97 \\
2 & 09.3 .1998 & 23.94 & 17.93 & 31.72 & 2.41 \\
3 & 03.2 .2000 & 23.28 & 18.38 & 32.05 & 1.92 \\
4 & 22.2 .2010 & 25.25 & 20.62 & 33.56 & 2.39 \\
5 & 12.2 .2018 & 26.72 & 20.61 & 34.51 & 2.94 \\
\hline
\end{tabular}

of the study area. When surface temperature increases, the amount of NDVI value decreases. This is the most common behavior found in grassland and sparse vegetation areas.

\subsection{Retrieval of Surface Temperature from the Land Use Land Cover Indices}

This technique of using temperature forecast to estimate LST pattern to model and estimate UHI is one such contribution of this study. As presented in Table 4 and Figure 4, For the Polynomial curve fitting analysis of land surface temperature distribution the Urban Index (UI) and Modification of normalized difference water index (MNDWI) were chosen as the predictors [5]. The regression model was tested on an independent Landsat information acquired in February 2010 and February 2018 and the model nearly resembled like the temperature patterns (Figure 5, Figure 6). Based on the Information acquired from independent Landsat in 2018 Regression model was tested. Temperature redeemed from UI and MNDWI based on their direct relation to thermal infrared information (Band 10) of Landsat 8. Based on 161 points samples over the inspected region, the UI and MNDWI forecasted surface temperature with advanced correctness (mean relative rate percentage $5.88 \%$, and $4.41 \%$ with root mean square error $1.61^{\circ} \mathrm{C}, 1.31^{\circ} \mathrm{C}$ and ration RMSE/std are 0.5 and 0.44 for 2010 and 2018 respectively.

\subsection{Predicted Temperature Distribution in Freetown up to the Year 2026}

The rising temperature patterns observed between 2000 and 2018 may proceed through 2026 (Table 5) and Figure 7. The scope of high-temperature classification (greater than $35^{\circ} \mathrm{C}$ ) was predicted to increase to the detriment of low-temperature classes. According to LST's values, the predicted values in 2026 were more than the simulated value in 2018. However, in the predictions for South-eastern regions where low-density residential areas are found were moderately cooler than Northern-eastern regions where high-density residential areas are found. Predictions demonstrate that land surface temperatures underneath $32^{\circ} \mathrm{C}$ will possibly stay common in the northern half, where low and medium density residential is found. Besides, expecting that development patterns observed between 2000 and 2018 endure, the extension would high-density built-up areas would bring about high surface temperatures (over $35^{\circ} \mathrm{C}$ ) in eastern regions, 
such as in high-density residential areas. It is worth noting that the LST expanded for all land cover types.

Table 4. Correlation analysis of LST vs. Difference Indies 1988, 1998, 2000, 2010 and 2018.

\begin{tabular}{cccccc}
\hline \multirow{2}{*}{$\begin{array}{c}\text { Correlation } \\
\text { analysis }\end{array}$} & Year & Indices & Multi Linear regression & $\mathrm{R}$ & $\mathrm{R}^{2}$ \\
\cline { 2 - 6 } & 1988 & MNDWI UI & LST $=7.65^{\star} \mathrm{UI}+3.13^{\star} \mathrm{MNDWI}+25.1$ & 0.89 & 0.80 \\
1 & 1998 & MNDWI UI & LST $=16.7^{\star} \mathrm{UI}-6.56^{\star} \mathrm{MNDWI}+28.12$ & 0.91 & 0.83 \\
2 & 2000 & MNDWI UI & LST $=14.9^{\star} \mathrm{UI}-5.68^{\star} \mathrm{MNDWI}+27.01$ & 0.88 & 0.78 \\
4 & 2010 & MNDWI UI & LST $=12.4^{*} \mathrm{UI}-4.84^{\star} \mathrm{MNDWI}+28.32$ & 0.90 & 0.81 \\
5 & 2018 & MNDWI UI & LST $=24.9^{*} \mathrm{UI}-44.7^{*} \mathrm{MNDWI}+29.11$ & 0.92 & 0.84 \\
\hline
\end{tabular}

Table 5. Descriptive statistics of LST for different times.

\begin{tabular}{cccccc}
\hline \multirow{2}{*}{ Statistics Information } & \multicolumn{5}{c}{ Descriptive statistics of LST } \\
\cline { 2 - 6 } & YEAR & Mean & Min & Max & St \\
\cline { 2 - 6 } 1 & 26.12 .1988 & 21.23 & 17.11 & 30.83 & 1.97 \\
2 & 09.3 .1998 & 23.94 & 17.93 & 31.72 & 2.41 \\
3 & 03.2 .2000 & 23.28 & 18.38 & 32.05 & 1.92 \\
4 & 22.2 .2010 & 25.25 & 20.62 & 33.56 & 2.39 \\
6 & 12.2 .2018 & 26.72 & 20.61 & 34.51 & 2.94 \\
\hline
\end{tabular}

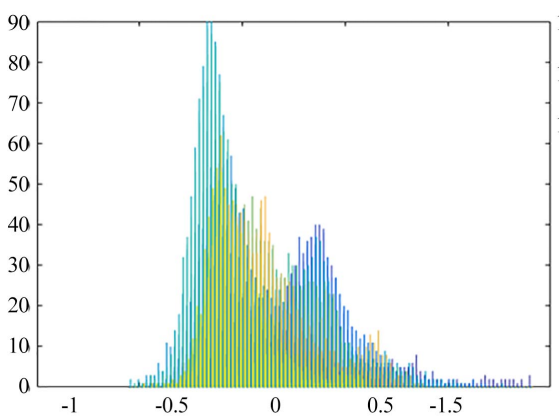

(a)

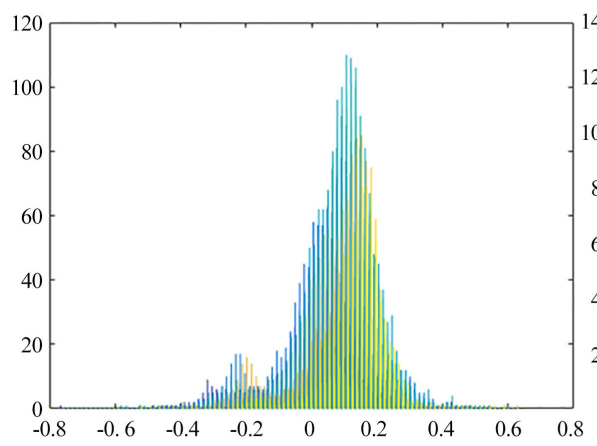

(c)

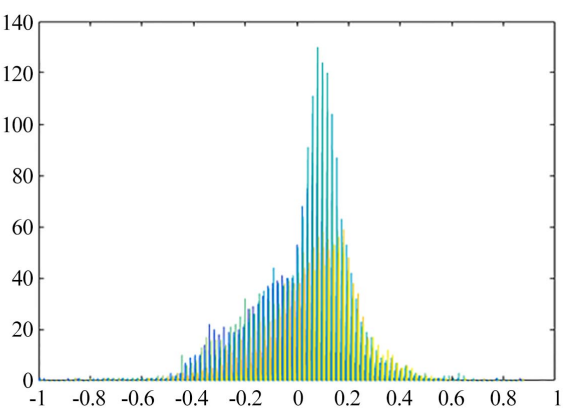

(b)

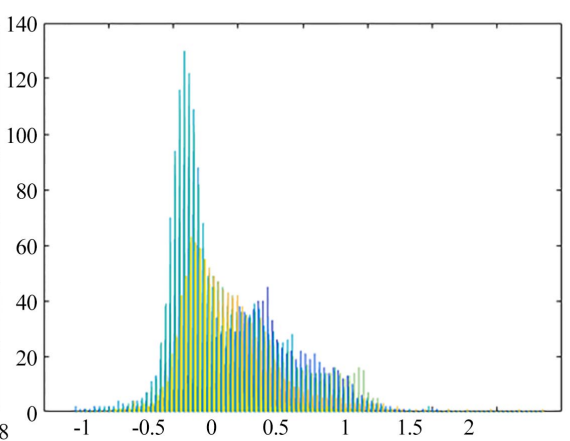

(d)

Figure 4. Frequency of occurrence versus MNDWI (a), UI (b), MNDWI (c), UI (d)-residuals for 2010, 2018. 


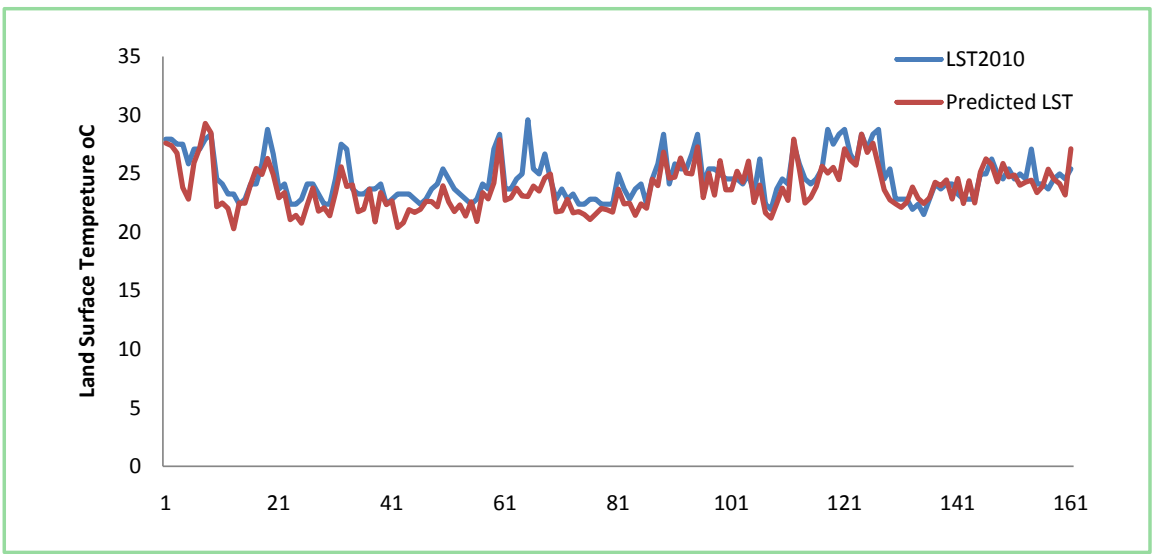

Figure 5. Comparison of surface temperature derived from a thermalband with derived from the LULC Indices for 2010.

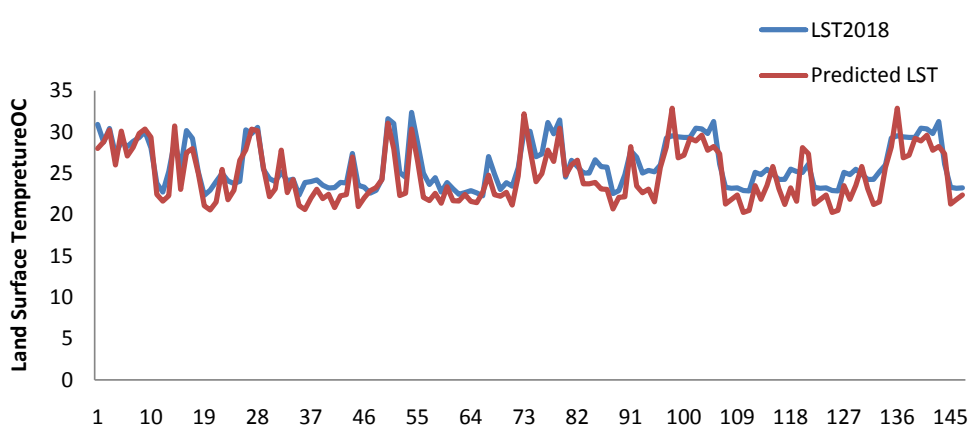

Figure 6. Comparison of surface temperature derived from a thermalband with derived from the LULC Indices for 2018.

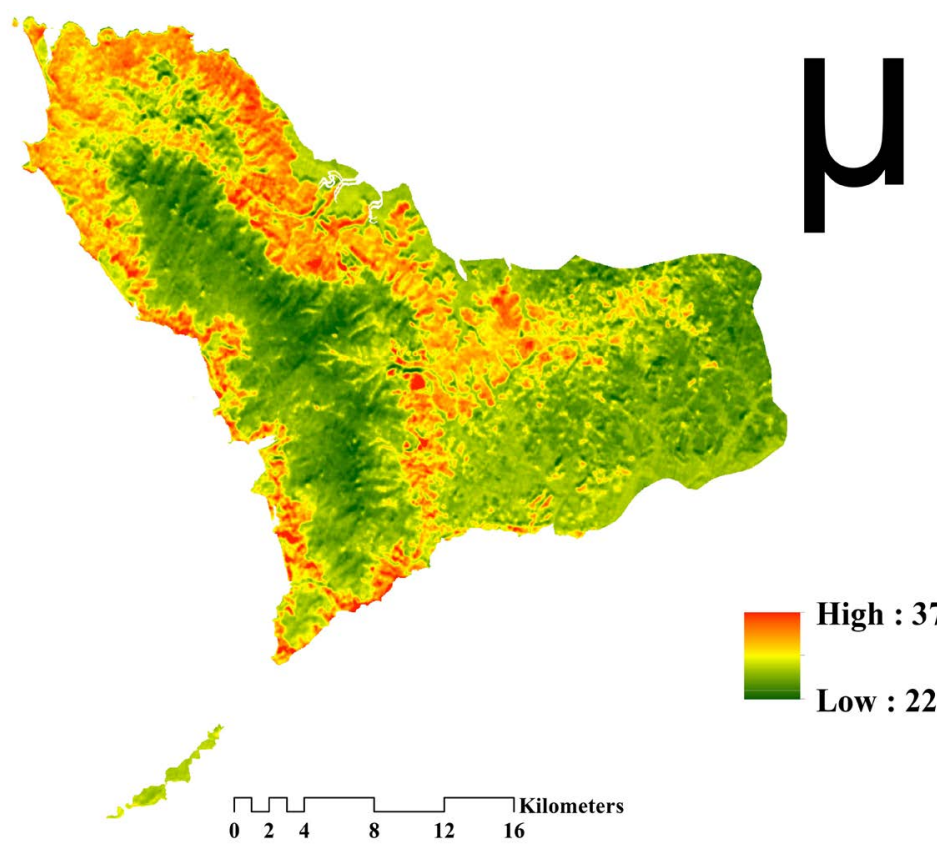

Figure 7. LST map of Freetown city in 2030. 


\section{Conclusions and Outlook}

The investigation aims to forecast future distribution of land surface temperatures in Freetown utilizing the Polynomial curve fitting analysis. The research used two land cover indices (e.g., MNDWI and UI) and implemented a multi-regression equation to predict future LST. We declare that the Urban Index (UI) and (MNDWI) predicted surface temperature with high accuracy (mean relative rate percentage $5.88 \%, 4.41 \%$, and root mean square error $1.63^{\circ} \mathrm{C}, 1.31^{\circ} \mathrm{C}$, and ration RMSE/std are 0.5 and 0.44 for 2010 and 2018 respectively). Urban expansion development will be accompanied by surface temperature increments, especially in Freetown's western metropolitan area. The temperature that dominates the west urban region may increase in the city between 2000 and 2018 may proceed through 2026. For example, different factors, such as effective mitigation procedures and changes in city development policies, can impact surface temperature patterns. By and large, this study's discoveries underscore the significance of medium resolution satellite information in foreseeing future surface temperatures in urban settings. However, there is a need for future studies to explore the feasibility of these methods and techniques at national or regional spatial levels.

\section{Conflicts of Interest}

The authors declare no conflicts of interest regarding the publication of this paper.

\section{References}

[1] Buyantuyev, A. and Wu, J. (2010) Urban Heat Islands and Landscape Heterogeneity: Linking Spatiotemporal Variations in Surface Temperatures to Land-Cover and Socioeconomic Patterns. Landscape Ecology, 25, 17-33. https://doi.org/10.1007/s10980-009-9402-4

[2] Ikechukwu, M., et al. (2016) Prediction of Land Surface Temperature (LST) Changes within Ikon City in Nigeria Using Artificial Neural Network (ANN). International Journal of Remote Sensing Applications, 6, 96-107. https://doi.org/10.14355/ijrsa.2016.06.010

[3] Amiri, R., et al. (2009) Spatial-Temporal Dynamics of Land Surface Temperature in Relation to Fractional Vegetation Cover and Land Use/Cover in the Tabriz Urban Area, Iran. Remote Sensing of Environment, 113, 2606-2617. https://doi.org/10.1016/j.rse.2009.07.021

[4] Song, J., et al. (2014) The Relationships between Landscape Compositions and Land Surface Temperature: Quantifying Their Resolution Sensitivity with Spatial Regression Models. Landscape and Urban Planning, 123, 145-157. https://doi.org/10.1016/j.landurbplan.2013.11.014

[5] Mustafa, E.K., et al. (2019) Simulation of Land Use Dynamics and Impact on Land Surface Temperature Using Satellite Data. GeoJournal, 1-19. https://doi.org/10.1007/s10708-019-10115-0

[6] Maduako, I., Yun, Z. and Patrick, B. (2016) Simulation and Prediction of Land Surface Temperature (LST) Dynamics within Ikom City in Nigeria Using Artificial Neural Network (ANN). Journal of Remote Sensing \& GIS, 5, 158. 
[7] Mushore, T.D., et al. (2017) Prediction of Future Urban Surface Temperatures Using Medium Resolution Satellite Data in Harare Metropolitan City, Zimbabwe. Building and Environment, 122, 397-410. https://doi.org/10.1016/j.buildenv.2017.06.033

[8] Tarawally, M., et al. (2018) Comparative Analysis of Responses of Land Surface Temperature to Long-Term Land Use/Cover Changes between a Coastal and Inland City: A Case of Freetown and Bo Town in Sierra Leone. Remote Sensing, 10, 112. https://doi.org/10.3390/rs10010112

[9] Weng, Q., Lu, D. and Schubring, J. (2004) Estimation of Land Surface Temperature-Vegetation Abundance Relationship for Urban Heat Island Studies. Remote sensing of Environment, 89, 467-483. https://doi.org/10.1016/j.rse.2003.11.005

[10] Sobrino, J.A., Jiménez-Muñoz, J.C. and Paolini, L. (2004) Land Surface Temperature Retrieval from LANDSAT TM 5. Remote Sensing of Environment, 90, 434-440. https://doi.org/10.1016/j.rse.2004.02.003

[11] Markham, B.L. (1986) Landsat MSS and TM Post-Calibration Dynamic Ranges, Exoatmospheric Reflectances and At-Satellite Temperatures. Landsat Technical Notes, 1, 3-8.

[12] Weng, Q. (2001) A Remote Sensing? GIS Evaluation of Urban Expansion and Its Impact on Surface Temperature in the Zhujiang Delta, China. International Journal of Remote Sensing, 22, 1999-2014. https://doi.org/10.1080/01431160152043676

[13] Nichol, J.E. (1994) A GIS-Based Approach to Microclimate Monitoring in Singapore's High-Rise Housing Estates. Photogrammetric Engineering and Remote Sensing, 60, 1225-1232.

[14] Sobrino, J., Caselles, V. and Becker, F. (1990) Significance of the Remotely Sensed Thermal Infrared Measurements Obtained over a Citrus Orchard. ISPRS Journal of Photogrammetry and Remote Sensing, 44, 343-354. https://doi.org/10.1016/0924-2716(90)90077-O

[15] Stone, B., Hess, J.J. and Frumkin, H. (2010) Urban Form and Extreme Heat Events: Are Sprawling Cities More Vulnerable to Climate Change than Compact Cities? Environmental Health Perspectives, 118, 1425-1428. https://doi.org/10.1289/ehp.0901879

[16] Zha, Y., Gao, J. and Ni, S. (2003) Use of Normalized Difference Built-Up Index in Automatically Mapping Urban Areas from TM Imagery. International Journal of Remote Sensing, 24, 583-594. https://doi.org/10.1080/01431160304987

[17] Kawamura, M., Jayamana, S. and Tsujiko, Y. (1996) Relation between Social and Environmental Conditions in Colombo Sri Lanka and the Urban Index Estimated by Satellite Remote Sensing Data. International Archives of the Photogrammetry and Remtesensing, 31, 321-326.

[18] Tucker, C.J. (1979) Red and Photographic Infrared Linear Combinations for Monitoring Vegetation. Remote Sensing of Environment, 8, 127-150. https://doi.org/10.1016/0034-4257(79)90013-0

[19] Gutman, G. and Ignatov, A. (1998) The Derivation of the Green Vegetation Fraction from NOAA/AVHRR Data for Use in Numerical Weather Prediction Models. International Journal of Remote Sensing, 19, 1533-1543. https://doi.org/10.1080/014311698215333

[20] Kumar, D. and Shekhar, S. (2015) Statistical Analysis of Land Surface Temperature-Vegetation Indexes Relationship through Thermal Remote Sensing. Ecotoxicology and Environmental Safety, 121, 39-44.

https://doi.org/10.1016/j.ecoenv.2015.07.004 
[21] Liu, L. and Zhang, Y. (2011) Urban Heat Island Analysis Using the Landsat TM Data and ASTER Data: A Case Study in Hong Kong. Remote Sensing, 3, 1535-1552. https://doi.org/10.3390/rs3071535 